\title{
A critical appraisal of what organisational approaches are pivotal to improve patient safety
}

\author{
Jeong-ah Kim*1, Daniel Terry ${ }^{1}$, Sunny Jang ${ }^{2}$, Julia Gilbert ${ }^{1}$, Mary Cruickshank ${ }^{1}$ \\ ${ }^{1}$ School of Nursing and Healthcare Professions, Federation University Australia, Ballarat, Australia \\ ${ }^{2}$ Wicking Dementia Research and Education Centre, University of Tasmania, Hobart, Australia
}

Received: November 8, 2019

DOI: $10.5430 /$ jha.v9n $1 \mathrm{p} 26$
Accepted: December 24, 2019 Online Published: January 12, 2020

URL: https://doi.org/10.5430/jha.v9n1p26

\begin{abstract}
Background: Patient safety remains a priority for healthcare organisations globally. There remains little consensus regarding the extent of this issue and the resultant impact on both individuals and communities.

Aim: Our study aims to provide healthcare organisations and decision makers with increased information regarding predictive risk factors to enhance patient safety, and develop an organisational culture of safety.

Methods: This paper reviews current literature regarding patient safety and presents predictive risk factors and recommendations for healthcare organisations globally to measure and monitor patient safety.

Results: Three categories of organisational factors promoting safety culture were identified - Focusing on system/culture, management support and team work and event reporting.

Conclusions: This review strove to identify and discuss the predictive risk factors for patient safety and support the importance of a positive organisational culture and strong leadership in monitoring and reducing patient care errors and improving patient care in healthcare setting.
\end{abstract}

Key Words: Patient safety, Safety culture, Safety system, Event reporting, Management support, Predictive risk factors

\section{INTRODUCTION}

The issue of medical errors has increased over the past five years with the World Health Organisation (2017) addressing patient safety as one of its key global challenges, estimating medical errors cost the global healthcare system US $\$ 42$ billion annually. The Australian government has revealed that preventable medical errors in hospitals are responsible for $11 \%$ of all deaths in Australia or 1 in every 9 deaths. ${ }^{[1]}$ In Australia, up to three per cent of hospital admissions are due to medical errors, costing \$AU1.2 billion dollars per year. The Australian government has also revealed that up to 18,000 people potentially die each year with 50,000 people experiencing a permanent harm due to medical error, how- ever, there remains no systematic national collection and linking medical error data across healthcare. This continues to impact the ability to gauge the seriousness of the current situation. ${ }^{[1]}$ More than 5 million people have been killed by Western health practice in the past decade (Europe, United States, Canada, Australia, and New Zealand) and at least 20 million killed or permanently harmed globally. In addition, the economic impact due to preventable medical error and deaths is up to US\$1 trillion over the past decade. ${ }^{[2]}$ Although estimates of the size of the problem are often sporadic, particularly in countries in transition and economically developing nations, it is anticipated that millions of healthcare consumers worldwide experience disabilities, injuries

${ }^{*}$ Correspondence: Jeong-ah Kim; Email: j.kim@federation.edu.au; Address: School of Nursing and Healthcare Professions, Federation University Australia, PO Box 663, Ballarat VIC 3353, Australia. 
or death due to poor healthcare. ${ }^{[3]}$

In past years, safety measures have been established on retrospective data of employee fatalities and injuries in high hazard industries such as aviation, nuclear energy, and shipping. Recently, with increasing awareness of organisational, managerial, and human factors, more emphasis has been placed on predictive measures of safety rather than technical failures as primary source of error in these industries. ${ }^{[4]}$ While newly established organisation such as Safer Care Victoria (2017) or the Australian Commission on Safety and Quality in Health Care in Australia recognises the importance of governance, leadership, culture, patient safety systems in delivering quality care, such approaches have received very little attention within the healthcare industry despite it being considered a high hazard industry. This has resulted in lack or absence of data to predict the occurrence of adverse health events, and lack of awareness about important relationships between organisational determinants and clinical outcomes. ${ }^{[5]}$ It is important to note that a strong safety "culture" environment can be a critical element for organisational success for patient safety. ${ }^{[6]}$

The aim of this study was to provide a critical appraisal of the key elements to improve patient safety culture within healthcare settings. It seeks to provide audiences with a better understanding of the importance of predictive risk factors to enhance patient safety culture. In addition, it strives to identify studies that address the risk factors that impact a positive patient safety culture, minimise patient harm, and may be a valuable tool to support developing and improving a safety culture within an organisation.

\section{Methods}

To facilitate the identification and evaluation of potential risk factors for improving patient safety culture, the authors identified safety factors including possible approaches, and strategies that contribute to a positive patient safety culture. In addition to including explicit inclusion and exclusion criteria the approach sought to assess each individual factor in terms of its efficacy, study design and study outcomes. The databases used were researched between July 2018 and January 2019 and included: CINAHL, Cochrane, PsychINFO, EBSCO, MEDLINE and Web of Science using the search terms "predictive risk factors", "medical errors", "patient safety climate", "organisational and/or organizational factors", "health care", and "safety culture". Studies were included: (1) If they indicated improving a culture or climate of patient safety; (2) If any used a valid measure to assess patient safety culture; (3) if any included adequate data to predict patient safety culture and climate; (4) if papers were published in English. The review also examined grey literature such as government reports, policy statements, issues papers, Doctor of Philosophy $(\mathrm{PhD})$ theses.

Studies and literature were excluded if they focused on only survey development or tools to assess the culture. Initially, references were screened for relevance with literature relating to organisational factors being used as a primary source to investigate the influences of organisational factors that improved a culture of patient safety.

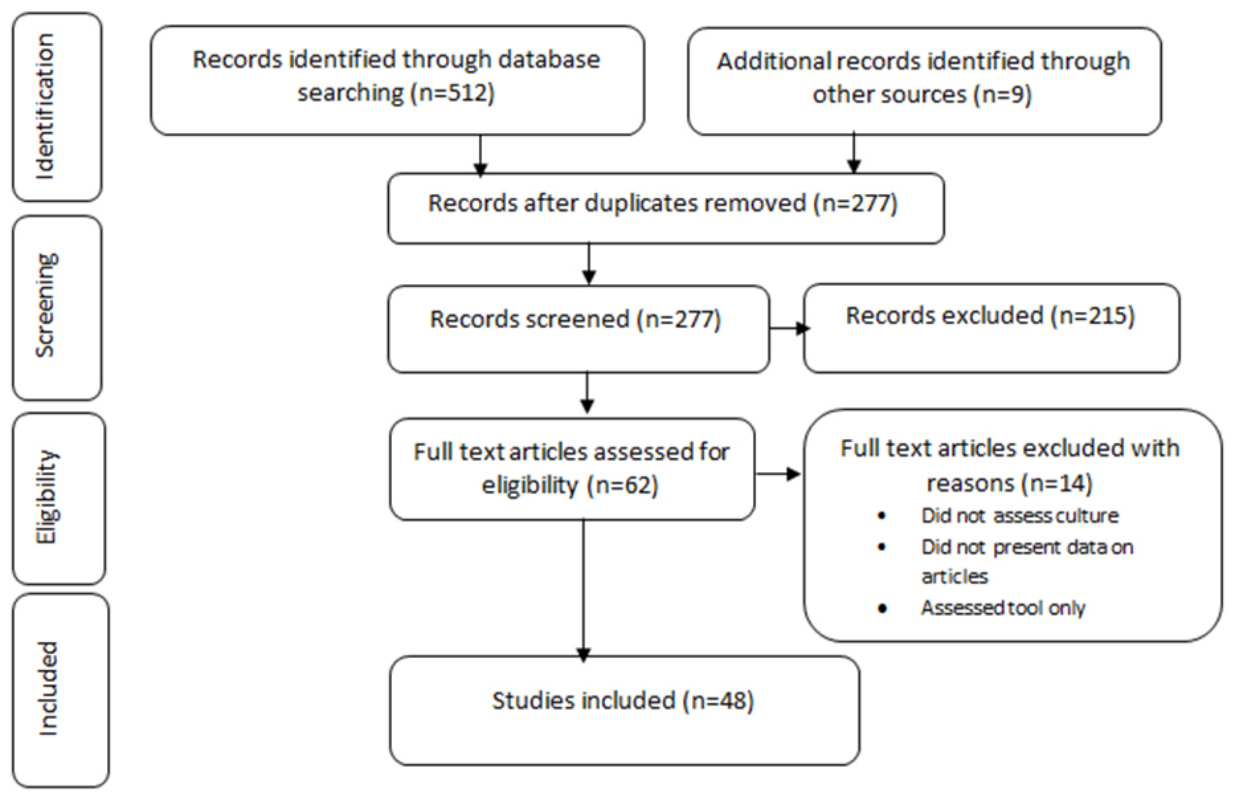

Figure 1. PRISMA flow diagram of the procedure for selecting publications for the review 
A total of 512 studies were selected, all of which were independently screened by 2 reviewers (JK, DT). Abstracts of the 277 articles meeting the inclusion criteria were used; full-text articles were retrieved when the abstract was provided insufficient information. To assure reliability of this categorisation, an independent reviewer (JK, DT) assessed a randomly selected $20 \%$ subset of the abstracts. The disagreement proportion was 0.875 . A total of 48 studies meeting the selection criteria were identified for final inclusion. An overview of the studies investigating predictive risk factors for improving patient safety is provided (see Figure 1).

\section{Results}

Throughout the critical appraisal, three categories of organisational factors for promoting safety culture were identified:
Focusing on system/ culture: The systems and organisational centred approach assumes that humans could inevitably make mistakes or be wrong and that systems must be employed so that humans are prevented from making errors. Management support and team work: Leadership in management encourages and rewards recognition, two-way communication, senior staff involvement, feedback, non-punitive response to error, and job satisfaction. Event reporting: Reporting of adverse events, near misses, and openness, structure and frequency of reporting is the key healthcare management structure.

Table 1 provides a description of the studies for predictive factors in improving quality and safety of patient and each of the three themes are discussed in detail below.

Table 1. Predictive factors improving quality and safety of patient

\begin{tabular}{|c|c|c|}
\hline Source & Predicting factors & Key findings \\
\hline Benn J et al., (2012) & Team work, collaboration & $\begin{array}{l}\text { Multi-professional collaboration and extent of process measurement were significant } \\
\text { predictors of change in SCC. Hospital type and size, along with a range of } \\
\text { programme preconditions, were not found to be significant. }\end{array}$ \\
\hline $\begin{array}{l}\text { Jeffcott SA, Mackenzie DF } \\
(2008)\end{array}$ & Team work & $\begin{array}{l}\text { Effective team performance is important to measure in order to determine how } \\
\text { clinicians should be trained for safe and effective patient care. }\end{array}$ \\
\hline Lawton et al ., (2015) & $\begin{array}{l}\text { Patient involvement and } \\
\text { feedback }\end{array}$ & $\begin{array}{l}\text { Feedback from patients about the safety of the care that they receive can be used as a } \\
\text { predicting fact to improve health care service. }\end{array}$ \\
\hline O’Brian et al., (2009) & $\begin{array}{l}\text { Event reporting, } \\
\text { communication about error }\end{array}$ & $\begin{array}{l}\text { The correlations with perceived outcomes (event reporting, overall perceptions of } \\
\text { safety, and safety grade) were strongest and most consistent for the unit dimensions } \\
\text { of supervisor/manager expectation for safety and feedback and communication about } \\
\text { error, which were associated with all } 3 \text { outcomes both before and after the } \\
\text { intervention. }\end{array}$ \\
\hline Pfeiffer, Manser (2010) & $\begin{array}{l}\text { Feedback about error, } \\
\text { communication openness }\end{array}$ & Feedback about error and communication openness is the most relevant predictor. \\
\hline $\begin{array}{l}\text { Rivard, Rosen \&Carroll } \\
\text { (2006) }\end{array}$ & Organisational learning & $\begin{array}{l}\text { Patient safety improvement requires organisational learning at the system level, } \\
\text { which entails changes in organisational routines that cut across divisions, } \\
\text { professions, and levels of hierarchy. }\end{array}$ \\
\hline $\begin{array}{l}\text { Verbeek-van Noord, } \\
\text { Cordulawagner (2014) }\end{array}$ & Event reporting & $\begin{array}{l}\text { "Frequency of event reporting" and "hospital management support for patient } \\
\text { safety". }\end{array}$ \\
\hline Helling et al., (2004) & Management support & $\begin{array}{l}\text { Significant improvement was observed for the "hospital management support for } \\
\text { patient safety" dimension - all main effects were found to be significant full stop. }\end{array}$ \\
\hline Bryan et al., (2006) & $\begin{array}{l}\text { Collaborative work, } \\
\text { physician participating }\end{array}$ & $\begin{array}{l}\text { Involvement by multiple hospital units in the QI effort is associated with worse } \\
\text { values on all four patient safety indicators. }\end{array}$ \\
\hline $\begin{array}{l}\text { Great Britain. Health and } \\
\text { Safety Executive, Human } \\
\text { Engineering Limited (2005) }\end{array}$ & $\begin{array}{l}\text { Leadership, two-way } \\
\text { communication, employee } \\
\text { involvement, learning } \\
\text { culture, attitude towards } \\
\text { blame }\end{array}$ & $\begin{array}{l}\text { Her Majesty's Railway Inspectorate (HMRI) requested that the approach should } \\
\text { focus on a limited number of indicators that are known to influence safety culture. } \\
\text { The five indicators are as follows: Leadership, Two-way communication, Employee } \\
\text { involvement, Learning culture, Attitude towards blame. }\end{array}$ \\
\hline Wilson (2007) & Management support & $\begin{array}{l}\text { Hospital management and supervisor support does lead to improved perceptions of } \\
\text { safety. }\end{array}$ \\
\hline Pronovost et al., (2003) & $\begin{array}{l}\text { Management perceived } \\
\text { safety efforts }\end{array}$ & $\begin{array}{l}\text { Senior leaders need to become more visible to front line staff in their efforts to } \\
\text { improve patient safety. }\end{array}$ \\
\hline $\begin{array}{l}\text { Annemie Vlayen et al., } \\
\text { (2015) }\end{array}$ & Management support & $\begin{array}{l}\text { Improvements were observed for most safety culture dimensions with a major } \\
\text { significant improvement for "Management support for patient safety". }\end{array}$ \\
\hline Relihan et al., (2009) & $\begin{array}{l}\text { Safety climate, team work, } \\
\text { job satisfaction }\end{array}$ & $\begin{array}{l}\text { Acute medical admissions unit scored significantly higher for four of the six safety } \\
\text { domains: } \backslash .01 \text { for "teamwork climate", "safety climate" and "stress recognition" } \\
\text { and } p \backslash .05 \text { for "job satisfaction". }\end{array}$ \\
\hline $\begin{array}{l}\text { Cláudia Tartaglia Reis Sofia } \\
\text { Guerra Paiva Paulo Sousa } \\
\text { (2018) }\end{array}$ & $\begin{array}{l}\text { Organisational learning, } \\
\text { team work }\end{array}$ & $\begin{array}{l}\text { The dimensions that proved strongest were "Teamwork within units" and } \\
\text { "Organisational learning-continuous improvement". }\end{array}$ \\
\hline Sammer et al., (2010) & $\begin{array}{l}\text { Senior leadership } \\
\text { accountability teamwork, }\end{array}$ & $\begin{array}{l}\text { Seven subcultures of patient safety culture were identified: (a) leadership, (b) } \\
\text { teamwork, (c) evidence-based, (d) communication, (e) learning, (f) just, and (g) } \\
\text { patient-centred. This study found senior leadership accountability key to an } \\
\text { organisation-wide culture of safety. }\end{array}$ \\
\hline
\end{tabular}


Table 1 continued.

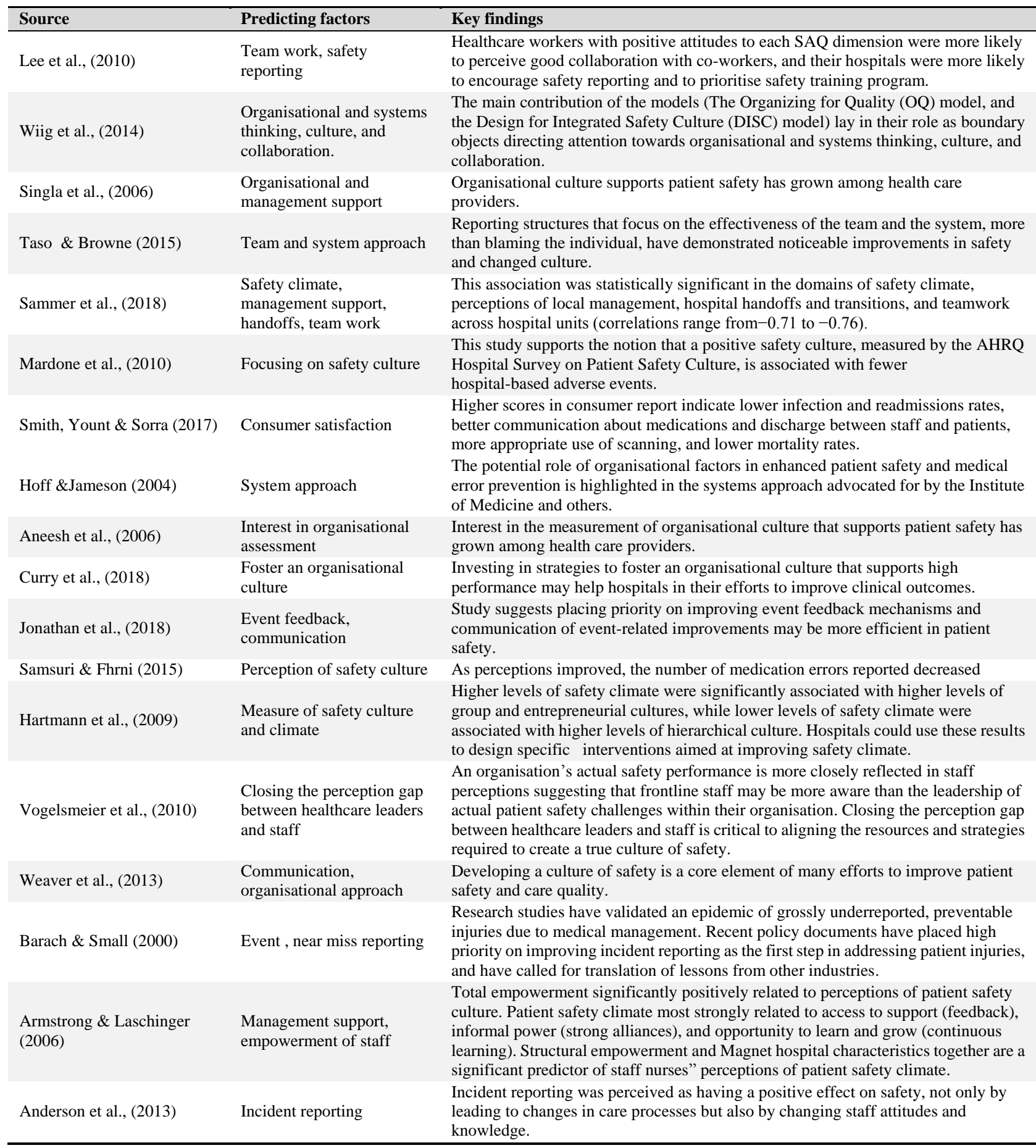

\subsection{Focusing on system/culture}

Although human nature is particularly prone to error and often contributes a critical role in the occurrence of errors, blaming individuals for being human is suggested to be an ineffective approach to improve patient safety. ${ }^{[7]}$ With this new focus on systems, processes are increasingly evident as factors that can have a pivotal role in reducing errors. More effective methods for improving patient safety have been found and these include developing a positive culture and increasing awareness of a desire to improving safety climate in the healthcare work environment. ${ }^{[8-13]}$

The most discussed and analysed predictive factors for a positive culture across the 48 studies focused on organisational and system factors. Twenty-five studies explicitly reported 
organisational factors as predictive factors for improving patient safety culture and reported them to be the most frequent contributory factors that promote a positive safety culture and prevent harm to patients. Of these, fourteen studies were systematic reviews and eleven studies did surveys on hospitals, patients, and health care staff to identify factors for patient safety in health care settings.

Studies that examined the linkages between organisational factors, medical errors and patient safety found the potential role of organisational factors in enhanced patient safety and medical error prevention are highlighted in the system approach. For example, a study of safety culture, measured using the Agency for Healthcare Research and Quality (AHRQ) Hospital Survey on Patient Safety Culture found that hospitals that scored more positively in terms of patient safety culture had lower rates of complications or adverse events. These findings support the idea that a more positive patient safety culture is associated with fewer adverse events in hospitals and improve quality and safety in healthcare. ${ }^{[9,13]}$

Other studies have confirmed that structures that focus on the effectiveness of the system and culture, rather than blaming the individual, have demonstrated noticeable improvements in safety and changed culture. ${ }^{[13]}$ These suggest that the majority of errors is more accurately caused by system and process failures as opposed to human failures. ${ }^{[14,15]}$ The five most common organisational factors identified as influencing a positive patient safety outcome were: a non-punitive response to error, teamwork, leadership (management support), policies and procedures, staffing, communication and reporting. ${ }^{[8,16,17]}$

\subsection{Management support}

There is evidence to suggest that patient safety culture is a systemic matter in complex healthcare organisations, and if human activity is not supported by senior management or systems, it will lead to significant damage on improving patient safety culture. ${ }^{[18]}$ Various studies regarding the relationship between positive safety cultures and contributing factors are of significant importance to safety culture aspects such as leadership, communication and management support. $^{[19,20]}$ In order to create a positive culture of patient safety and achieve a reduction in errors, the literature continually points to the role of leadership in administering a clear, supportive culture that nurtures individual efforts, ${ }^{[21]}$ and one that is non-punitive. ${ }^{[13,19]}$ This result is supported Curry et al. ${ }^{[12]}$ who found that hospital management and supervisor support leads to improved perceptions of safety. The link between this management support and outcomes suggests that employees are willing to report errors when they occur, but the low occurrence of such events in healthcare prevents the disclosure of healthcare mistakes. An argument that man- agement support could be the key factor for a positive safety culture is evidenced by another study ${ }^{[19]}$ which showed that overall perception of safety and the safety grade were predicted by supervisor/manager expectations promoting safety both before and after the intervention.

There is strong support for this argument from two European studies $^{[22,23]}$ which measured safety culture in the Belgian hospitals using validated translations of the Hospital Survey on Patient Safety Culture (HSOPSC). These studies found similar results that positive responses and improvements were observed for most safety culture dimensions with a significant improvement for "management support for patient safety". Another observational study ${ }^{[24]}$ provided evidence that management support to improve safety culture can be a meaningful factor as a safety attitudes questionnaire (SAQ) survey, scored significantly higher for "teamwork climate". This result suggests that Acute Medical Assessment Unit (AMAU) staff had significantly more positive attitudes, with regard to speaking out, feeling with support from others, collaboration with their colleagues/other professions and conflict resolution. Organisational culture cannot be addressed without organisational structure, including financial arrangements, or human resource initiatives and illustrates the need for full management involvement. ${ }^{[25]}$ Joint Commission on Accreditation of Healthcare Organizations (JCHAO) ${ }^{[26]}$ supports the notion that a patient safety committee, which contributes a powerful role in developing cultural transformation strategies for successfully achieving a "cultural fit" between hospital managers and the staff. The findings emphasise bringing together multidisciplinary groups while recognising that organisational complexities and their clinical and administrative authority structures are necessary for promoting hospital safety culture. Given what is known regarding the influence of senior level management, Pfeiffer \& Manser, ${ }^{[20]}$ in their study that tested for predictive validity by analysing the relationships between safety climate measures and outcome variables, concluded that the most relevant predictor, and the best predictor for outcome measure was unit management support for patient safety.

Overall, it is widely acknowledged in literature that upper level leadership in management is a crucial driver of successful organisational change. ${ }^{[18,21]}$ Clarke $^{[27]}$ argues that senior leadership must first establish direction in the organisation. Predicting a safety culture therefore requires a concomitant integration of management initiative and concrete action and a well organised team work plan.

\subsection{Reporting}

In order to achieve an opportune organisational quality and safety learning, adverse events or near miss data should be 
used as a valuable tools because they may act as leading indicators and may provide insight into factors that may contribute to a positive safety culture. Regarding this acknowledgement of the importance of reporting an incident, especially a near miss will not always be reported as there are various reasons provided for not disclosing. In a study that looked at the impact of mandatory, non-confidential error reporting systems, it was found that these systems highly discouraged error reporting. ${ }^{[28]}$ In this case, healthcare providers in each Australian state and territory do not have strict incident report requirements, and they are not obligated to report errors that do not meet certain criteria, such as infections, falls resulting in injuries, and problems with medication and medical devices ${ }^{[29]}$ that may cause harm to patients. This leads to a lack of general information availability and helps explain, partly, why the problem is hardly noticed. Since there is a general under-reporting of adverse medical events, such as medication errors and near misses and malpractice claims this has led to many healthcare providers not recognising the national patient safety problem as applicable to their organisation. ${ }^{[30]}$

However, in the context of patient safety, where the main goal is to reduce avoidable harm resulting from healthcare, experts argue that, "events reporting" have the potential to contribute continuously to learning, and in order to facilitate effective safety learning, near miss and incident data must be interpreted as a concern and the risk factors and suggest that a culture of learning is a useful intervention for improving patient safety. ${ }^{[31,32]}$

The authors analysed five studies that evaluated different methods of critical incident reporting. All articles describing organisational processes related to incident monitoring, use of feedback to improve safety and commentary upon the effects of a lack of feedback on error reporting were included. Articles were selected on the basis of their inclusion of descriptions of how information from incident monitoring was used to improve patient safety.

Systematic review on reporting of near miss system suggested that it offers greater benefits over adverse events as it provides more opportunities to analyse the latent safety issues and adverse events, and is a "valuable tool for preventing future incident". [33] These findings were welcomed by El-Jardali et al. ${ }^{[4]}$ who argued that incident reporting data set were vital as a predictive tool for systems improvements to prevent errors from reoccurring and in developing a culture of safety.

Another study concluded that incident reporting should be viewed as a tool that focuses attention on safety and has multi-level influences on organisational, team and individual practices, knowledge and attitudes. ${ }^{[28]}$ The authors argued that an incident reporting system not only leads to changes in care processes, but also leads to modifying staff attitudes and knowledge, while having an overall positive effect on safety practice. ${ }^{[28]}$ This finding is also consistent with a crosssectional survey ${ }^{[34]}$ that found associations, such as "teamwork across units", "frequency of event reporting", "communication openness", "feedback about and learning from errors", "hospital management support for patient safety", were statistically significant, and concluded that these factors are important predictors of staff-reported safety in the Emergency Department (ED). This is also supported by Clarke, ${ }^{[27]}$ who concluded that the reporting of near-miss and unsafe conditions was considered an important component of hospitalbased safety initiatives. It was also recommended that identifying risk factors for adverse events should be part of a crucial first step toward the prevention of errors, and remains vital for quality assurance. ${ }^{[35]}$

From the sources reviewed, a lack of constructive feedback from incident reporting has been highlighted as hindering the willingness of staff to report in the future, however, it is apparent that incident data can be transformed into beneficial improvements in functional patient safety culture. While the solutions should focus on changing and enhancing a positive cultural environment, patient safety reporting systems that are acceptable to the organisation and easy to use among healthcare staff may assist to reduce medical errors. ${ }^{[27,36]}$

\section{Discussion}

Overall, a number of elements were identified during the critical appraisal that contributes to predictive risk factors for a culture of patient safety. Each element identified was couched within three broad factors, which included organisational systems or culture, management and leadership, and incident reporting. As such, healthcare organisational structures need to be robust enough to develop and maintain a culture of safety, where patient safety should form a tangible building block for service delivery. Such positive culture must have safety at the forefront of all employees' minds, where blame is not perpetuated, but rather where safety and behaviours leading to safety are committed to all practices, interactions and discourses within a health service.

Embedded within the organisation, are the systems of an organisation that assist the application, enhancement, and contribution to the cultural practices of safety. For example, systems may include mitigating policies, preventative procedures, and reporting processes to prevent future errors. What may be considered a vital element or contributory to the safety systems is management initiatives, which includes not just senior management, but also middle and lower level 
of management within a health system. Again, like the health service building, management may be likened to the walls of the structure, which when built on the foundation remain strong and true. In this sense, the role of leadership in the management is to instil clear and supportive cultures that nurture and promote individual and team efforts and accountability concerning safety.

At the centre of leadership in management, whether formal or informal, are the communication and support that allow individuals to speak up without fear, the feeling of support by others, the capacity to collaborate with colleagues and other professionals to find solutions to safety or potential issues that may arise. The need for reporting, as the third overarching factor, may be considered like the roof within the health service building metaphor. Without such reporting processes, structures and systems in place, there is a lack of protection for employees, patients and the health system itself. Reporting systems allow harms to be detected, avoided, and mitigated.

Furthermore, these structures allow for a culture of safety to be learned among those who may be new to the service and perpetuated among those who are more seasoned employees. However, such reporting systems must be built around confidentiality, openness and no-blame which seek the opportunity to change behaviour or processes rather than mitigate poor publicity and legal actions. Although reporting does not predict safety culture, it does guide, support and enhance the capacity of individuals, teams and management to identify risk or adverse events and improve attitudes, learning, and knowledge around safety. As such, it has an effect on the culture of the health service in which it is situated.

Much like the physical and fundamental elements of a health service building, a positive culture, good leadership, and healthy systems in place are the three pillars of safety. It is the foundation, walls and roof which can ensure protection from the winds and weather and will provide safety to all patients. Although not fool-proof, these three broad factors will ensure patient safety can be achieved in the future. The challenge therefore is to ascertain if all three elements are present, robust enough, while identifying where gaps may be present and what solutions may be used to fortify and build better and safer structures now and into the future.

The growing emphasis of organisational factors in enhancing patient safety within healthcare settings have been highlighted over the last two decades. However the significant body of evidence in healthcare literature that could be considered as a practical resource for establishing the predictive risk factors for improving patient safety have not been readily utilised across health industries and countries. The findings of this review reiterates and enhances the general models of organisational safety as a leading predictor of patient safety outcomes, and this review will encourage the next phase of inquiry to establish a standardised list of contributing factors for better understanding of the patient safety phenomena in healthcare industries. Without this information, the concept of system approaches will be least likely to provide the required clear measures that we are seeking for.

Potential limitations of this review was the authors' decision not to undertake a meta-analysis. The rationale behind this is: the topics and findings of the studies included are very broad and difficult to generalise and compare, the studies involve a mix of comparisons with different comparators, outcomes are too diverse, some of the individual studies reported a risk of bias, they used different sampling strategies and were conducted in healthcare contexts at different state of development. These are situations in which meta-analysis can be an impediment to critical appraisal procedure and may generate an incorrect result.

\section{Conclusions}

With greater insight of the complexity of the sources of adverse events and their causal relation in healthcare settings, the response to improve patient safety has been directed to modern health and safety management practice that is focusing more on management and organisational factors in depth. While the findings emphasised on safety culture across healthcare industries, a majority of the reviewed literature has focused on predictors of safety culture or has looked at safety culture in general as a mediator between a system centred approach, management actions and non-blame culture for reporting.

This review seeks to address the predictive risk factors for patient safety culture and suggests that an understanding of predictive risk factors for a culture of patient safety is emerging and can be categorised into three board areas; system focus, management support, and the reporting of adverse event or near miss events leads to more positive safety cultures in healthcare organisations. As such, refining the technical skills of individual members in their organisation will not be the solution to achieving a safety culture, but required to pay greater attention to the system in which the individuals are found. In particular, evidence suggests that improving a positive culture may involve the coordinated efforts of multiple members of the healthcare team.

Currently, there is no explicit general agreement and guide about the best practice for investigating safety culture in specific healthcare contexts and many of these studies focus on 
safety culture or climate in general rather than examining which factors of safety culture or climate impacted those outcomes. Therefore, it is essential to initiate further research on how risk factors are most effectively measured, what are the gaps and how to utilise these data for developing the most effective patient safety culture and strategies in healthcare systems.

\section{CONFlicts OF Interest Disclosure}

The authors declare they have no conflicts of interest.

\section{REFERENCES}

[1] Australian Commission on Safety and Quality in Health Care (ACSQHC). Australian Safety and Quality Goals for Health Care. Development and Consultation Report. Australia; 2011.

[2] WHO. Patient Safety: Making health care safer: World Health Organization. 2017. Available from: https://apps.who.int/iris/ handle/10665/255507

[3] Pronovost P, Sexton B. Assessing safety culture: guidelines and recommendations. Quality \& Safety in Health Care. 2005; 14(4): 231-3. PMid: 16076784. https ://doi.org/10.1136/qshc. 200 5.015180

[4] El-Jardali F, Sheikh F, Garcia NA, et al. Patient safety culture in a large teaching hospital in Riyadh: baseline assessment, comparative analysis and opportunities for improvement. BMC Health Services Research. 2014; 14: 122. PMid: 24621339. https://doi.org/10 .1186/1472-6963-14-122

[5] Dekker SW. Reconstructing human contributions to accidents: the new view on error and performance. Journal of Safety Research. 2002; 33(3): 371-85. https://doi.org/10.1016/S0022-4375(02)0 0032-4

[6] Richter JP, McAlearney AS, Pennell ML. The influence of organizational factors on patient safety: Examining successful handoffs in health care. Health Care Magement Review. 2016; 41(1): 3241. PMid: 25029512. https://doi.org/10.1097/HMR. 000000 0000000033

[7] James JT. A new, evidence-based estimate of patient harms associated with hospital care. Journal of Patient Safety. 2013; 9(3): 1228. PMid: 23860193. https://doi.org/10.1097/PTS.0b013e $3182948 a 69$

[8] Tsao K, Browne M. Culture of safety: A foundation for patient care. Seminars in Pediatric Surgery. 2015; 24(6): 283-7. PMid: 26653161. https://doi.org/10.1053/j. sempedsurg. 2015.08.005

[9] Smith SA, Yount N, Sorra J. Exploring relationships between hospital patient safety culture and Consumer Reports safety scores. BMC Health Services Research. 2017; 17(1): 143. PMid: 28209151. https://doi.org/10.1186/s12913-017-2078-6

[10] Samsuri SE, Pei Lin L, Fahrni ML. Safety culture perceptions of pharmacists in Malaysian hospitals and health clinics: a multicentre assessment using the Safety Attitudes Questionnaire. BMJ Open. 2015; 5(11): e008889. PMid: 26610761. https://doi.org/10.1 136/bmjopen-2015-008889

[11] Sammer C, Hauck LD, Jones C, et al. Examining the Relationship of an All-Cause Harm Patient Safety Measure and Critical Performance Measures at the Frontline of Care. Journal of Patient Safety. 2018. PMid: 29420456. https://doi.org/10.1097/PTS.0000 000000000468

[12] Curry LA, Brault MA, Linnander EL, et al. Influencing organisational culture to improve hospital performance in care of patients with acute myocardial infarction: a mixed-methods intervention study. BMJ Quality \& Safety. 2018; 27(3): 207-17. PMid: 29101292. https://doi.org/10.1136/bmjqs-2017-006989
[13] Wiig S, Robert G, Anderson J, et al. Applying different quality and safety models in healthcare improvement work: Boundary objects and system thinking. Reliability Engineering \& System Safety. 2014; 125(0951-8320): 134-44.https://doi.org/10.1016/j.ress. 2 014.01 .008

[14] Singer S, Meterko M, Baker L, et al. Workforce perceptions of hospital safety culture: development and validation of the patient safety climate in healthcare organizations survey. Health Services Research 2007; 42(5): 1999-2021. PMid: 17850530. https ://doi.org/10 $.1111 / j .1475-6773.2007 .00706 . x$

[15] Yates GR, Bernd DL, Sayles SM, et al. Building and sustaining a systemwide culture of safety. Joint Commission Journal on Quality and Patient Safety. 2005; 31(12): 684-9. https ://doi .org/10.1 016/S1553-7250(05) 31089-0

[16] Colla JB, Bracken AC, Kinney LM, et al. Measuring patient safety climate: a review of surveys. Quality \& Safety in Health Care. 2005; 14(5): 364-6. PMid: 16195571. https://doi.org/10.1136/qs hc. 2005. 014217

[17] Sarac C, Flin R, Mearns K, et al. Hospital survey on patient safety culture: psychometric analysis on a Scottish sample. BMJ Quality \& Safety. 2011; 20(10): 842-8. PMid: 21690247. https: //doi.org/10.1136/bmjqs. 2010.047720

[18] Hutchinson A, Barach P. What is the role of healthcare managers in delivering safe care? Quality \& Safety in Health Care. 2003; 12(3): 161-2. PMid: 12792000. https://doi.org/10.1136/qhc.12.3 .161

[19] Hellings J, Schrooten W, Klazinga NS, et al. Improving patient safety culture. International Journal of Health Care Quality Assurance. 2010; 23(5): 489-506. PMid: 20845679. https://doi.org/10.1108/ 09526861011050529

[20] Pfeiffer Y, Manser T. Development of the German version of the Hospital Survey on Patient Safety Culture: Dimensionality and psychometric properties. Safety Science. 2010; 48(10): 1452-62. https://doi.org/10.1016/j.ssci.2010.07.002

[21] Ruchlin HS, Dubbs NL, Callahan MA. The role of leadership in instilling a culture of safety: lessons from the literature. Journal of Healthcare Management/American College of Healthcare Executives. 2004; 49(1): 47-58; discussion-9. PMid: 14768428. https://doi.org/10.1097/00115514-200401000-00009

[22] Hellings J, Schrooten W, Klazinga N, et al. Challenging patient safety culture: survey results. International Journal of Health Care Quality Assurance. 2007; 20(7): 620-32. PMid: 18030963. https : //doi.org/10.1108/09526860710822752

[23] Vlayen A, Schrooten W, Wami W, et al. Variability of patient safety culture in Belgian acute hospitals. Journal of Patient Safety. 2015; 11(2): 110-21. PMid: 24080722. https://doi .org/10.1097/PT S. $0 \mathrm{~b} 013 \mathrm{e} 31829 \mathrm{c} 74 \mathrm{a} 3$

[24] Relihan E, Glynn S, Daly D, et al. Measuring and benchmarking safety culture: application of the safety attitudes questionnaire to an acute medical admissions unit. Irish Journal of Medical Science. 
2009; 178(4): 433-9. PMid: 19437091. https://doi.org/10.1 007/s11845-009-0352-2

[25] Davies HT, Nutley SM, Mannion R. Organisational culture and quality of health care. Quality in Health Care : QHC. 2000; 9(2): 111-9. PMid: 11067249. https://doi.org/10.1136/qhc.9.2.111

[26] Joint Commission on Accreditation of Healthcare Organizations (JCAHO). Patient safety committee: the foundation of a safety culture. Joint Commission Perspectives on Patient Safety. 2004; 1-4.

[27] Clarke JR. How a system for reporting medical errors can and cannot improve patient safety. The American Surgeon. 2006; 72(11): 1088-91; discussion 126-48.

[28] Anderson JE, Kodate N, Walters R, et al. Can incident reporting improve safety? Healthcare practitioners' views of the effectiveness of incident reporting. International Journal for Quality in Health Care. 2013; 25(2): 141-50. PMid: 23335058. https: //doi.org/10.1093/intqhc/mzs081

[29] Australian Institute of Health and Welfare (AIHW). Australia's health 2018. Australia's health series no. 16. AUS 221. Canberra: AIHW. 2018.

[30] Yoon RS, Alaia MJ, Hutzler LH, et al, 3rd. Using "near misses" analysis to prevent wrong-site surgery. Journal for Healthcare Quality. 2015; 37(2): 126-32. PMid: 24033453. https://doi.org/10.1 111/jhq. 12037

[31] Benn J, Burnett S, Parand A, et al. Factors predicting change in hospital safety climate and capability in a multi-site patient safety collaborative: a longitudinal survey study. BMJ Quality \& Safety. 2012; 21(7): 559-68. PMid: 22562874. https://doi.org/10.1 136/bmjqs-2011-000286

[32] Rivard PE, Rosen AK, Carroll JS. Enhancing patient safety through organizational learning: Are patient safety indicators a step in the right direction? Health Services Research. 2006; 41(4 Pt 2): 1633 53. PMid: 16898983. https://doi.org/10.1111/j.1475-677 3.2006.00569.x

[33] Barach P, Small SD. Reporting and preventing medical mishaps: lessons from non-medical near miss reporting systems. BMJ (Clinical research ed). 2000; 320(7237): 759-63. PMid: 10720361. https://doi.org/10.1136/bmj.320.7237.759

[34] Verbeek-Van Noord I, Wagner C, Van Dyck C, et al. Is culture associated with patient safety in the emergency department? A study of staff perspectives. International Journal for Quality in Health Care. 2013; 26(1): 64-70. PMid: 24334232. https ://doi.org/10.109 3/intqhc/mzt087

[35] Snijders C, Kollen BJ, van Lingen RA, et al. Which aspects of safety culture predict incident reporting behavior in neonatal intensive care units? A multilevel analysis. Critical Care Medicine. 2009; 37(1): 61-7. PMid: 19050606. https://doi.org/10.1097/CCM.0b01 3e31819300e4

[36] Sheikhtaheri A. Near Misses and Their Importance for Improving Patient Safety. Iranian Journal of Public Health. 2014; 43(6): 853-4. 